\title{
European Journal of Nutrition
}

\section{Antiproliferative activity of vitexin-2-O-xyloside and avenanthramides on CaCo-2 and HepG2 cancer cells occurs through apoptosis induction and reduction of pro-survival mechanisms \\ --Manuscript Draft--}

Manuscript Number:

Full Title:

Article Type:

Keywords:

Corresponding Author:

Corresponding Author Secondary

Information:

Corresponding Author's Institution:

University of Urbino "Carlo Bo"

Corresponding Author's Secondary Institution:

First Author:

Emanuele Salvatore Scarpa

First Author Secondary Information:

Order of Authors:

Emanuele Salvatore Scarpa

Elena Antonini

Francesco Palma

Michele Mari

Paolino Ninfali, Ph.D

Order of Authors Secondary Information:

Funding Information:

University of Urbino "Carlo Bo"

Not applicable
Purpose - CaCo-2 colon cancer cells and HepG2 liver cancer cells represent two malignant cell lines, which show a high resistance to apoptosis induced by conventional anticancer drugs. Vitexin-2-O-xyloside (XVX) and avenanthramides (AVNs) are naturally occurring dietary agents from Beta vulgaris var. cicla $\mathrm{L}$. and Avena sativa L., respectively. The aim of this work was to evaluate the antiproliferative effects and the reduction of the pro-survival mechanisms exerted by XVX and AVNs, used individually and in combination, in CaCo-2 and HepG2 cancer cells.

Methods - XVX and AVNs were isolated by liquid chromatography and characterized by HPLC-PDA-MS. The XVX and AVN antiproliferative effects were evaluated through sulforhodamine $B$ method, while their pro-apoptotic effects through caspase activity assays. RTqPCR was used to investigate the modulation of the pro-survival factors Baculoviral Inhibitor of apoptosis Repeat-Containing 5 (BIRC5), Hypoxia Inducible Factor $1 \alpha(H I F 1 A)$ and Vascular Endothelial Growth Factor (VEGFA). Cellular antioxidant activity (CAA) was investigated by means of DCFH-DA assay, whereas chemical antioxidant capacity was evaluated by the ORAC method.

Results - XVX and AVNs, both individually and in combination, inhibited the proliferation of CaCo-2 and HepG2 cancer cells, through activation of caspases 9, 8 and 3. XVX and AVNs downregulated the pro-survival genes BIRC5, HIF1A and VEGFA. The CAA assay showed that AVNs exhibited strong antioxidant activity inside both $\mathrm{CaCo}-2$ and HepG2 cells.

Conclusions - The antiproliferative activity of the XVX+AVNs mixture represents an 
innovative treatment, which is effective against two types of cancer cells characterized by high resistance to conventional anticancer drugs.

Suggested Reviewers:

Fulvia Farabegoli

fulvia.farabegoli@unibo.it

David M Peterson

dmpeter4@wisc.edu

Jeffrey B Blumberg

jeffrey.blumberg@tufts.edu

Maria Skoglund

maria.skoglund@Imv.slu.se 
Antiproliferative activity of vitexin-2-O-xyloside and avenanthramides on $\mathrm{CaCo}-2$ and HepG2 cancer cells occurs through apoptosis induction and reduction of pro-survival mechanisms Emanuele Salvatore Scarpa ${ }^{1}$, Elena Antonini ${ }^{1}$, Francesco Palma ${ }^{1}$, Michele Mari ${ }^{1}$ and Paolino Ninfali ${ }^{1 *}$

${ }^{1}$ Department of Biomolecular Sciences, University of Urbino "Carlo Bo", Urbino (PU) 61029, Italy

*Correspondence to: paolino.ninfali@ uniurb.it; Tel +39 0722 305288; Fax +39 0722305324

\section{Abstract}

Purpose CaCo-2 colon cancer cells and HepG2 liver cancer cells represent two malignant cell lines, which show a high resistance to apoptosis induced by conventional anticancer drugs. Vitexin-2-O-xyloside (XVX) and avenanthramides (AVNs) are naturally occurring dietary agents from Beta vulgaris var. cicla L. and Avena sativa L., respectively. The aim of this work was to evaluate the antiproliferative effects and the reduction of the pro-survival mechanisms exerted by XVX and AVNs, used individually and in combination, in CaCo-2 and HepG2 cancer cells.

Methods XVX and AVNs were isolated by liquid chromatography and characterized by HPLC-PDA-MS. The XVX and AVN antiproliferative effects were evaluated through sulforhodamine B method, while their pro-apoptotic effects through caspase activity assays. RTqPCR was used to investigate the modulation of the pro-survival factors Baculoviral Inhibitor of apoptosis Repeat-Containing 5 (BIRC5), Hypoxia Inducible Factor 1A (HIF1A) and Vascular Endothelial Growth Factor (VEGFA). Cellular antioxidant activity (CAA) was investigated by means of DCFH-DA assay, whereas chemical antioxidant capacity was evaluated by the ORAC method.

Results XVX and AVNs, both individually and in combination, inhibited the proliferation of CaCo-2 and HepG2 cancer cells, through activation of caspases 9, 8 and 3. XVX and AVNs downregulated the pro-survival genes BIRC5, HIF1A and VEGFA. The CAA assay showed that AVNs exhibited strong antioxidant activity inside both CaCo-2 and HepG2 cells.

Conclusions The antiproliferative activity of the $\mathrm{XVX}+\mathrm{AVNs}$ mixture represents an innovative treatment, which is effective against two types of cancer cells characterized by high resistance to conventional anticancer drugs.

Keywords Apoptosis; avenanthramides; CaCo-2 colon cancer cells; cellular antioxidant activity; HepG2 liver cancer cells; vitexin-2-O-xyloside.

Acknowledgments We acknowledge the financial support of University of Urbino "Carlo Bo". The authors wish also to thank: Terra Bio Soc. Coop. (Urbino, Italy) and Suba Seeds Company S.p.A. (Longiano, Italy) for providing oat grains and Beta vulgaris var. cicla L. seeds, respectively. Timothy Bloom is acknowledged for assistance in the English language. 
Beta vulgaris var. cicla $\mathrm{L}$. (BVc; Chenopodiaceae) contains flavonoids that derive from apigenin, namely vitexin, vitexin-2-O-rhamnoside and vitexin-2-O-xyloside (XVX), which can exploit antiproliferative activity in several tumor cell lines $[1,2]$. Studies have revealed that seeds of BVc are particularly rich in XVX, which has been purified in our laboratory and tested against RKO cells [3]. In these cells, it has been shown that XVX was able to induce apoptosis and to block the cell cycle in the G1 phase [3]. Moreover, in CaCo-2 and LoVo cancer cell lines, it has been shown that XVX was able to synergize with other anticancer phytochemicals, without any significant effect on the proliferation rate of normal cell lines $[4,5]$.

Oats (Avena sativa L.), which are normally consumed as whole grains, contain several antioxidant compounds, such as tocols, flavonoids, phenolic acids and avenanthramides [6]. Avenanthramides (AVNs), a group of substituted Ncinnamoylanthranilic acids, are soluble polyphenols exclusively found in oats, among cereals. More than 20 forms were identified by Collins in 1989, but the three most abundant are: AVN A, B and C, containing the $p$-coumaric, ferulic and caffeic acids, respectively, in the cinnamic moiety and the 5-hydroxyanthranilic acid in the anthranilic moiety [7].

AVN concentration varies considerably among varieties and it is influenced by genetic and environmental factors [8], as well as by the germination process $[9,10]$.

The bioavailability of AVNs has already been demonstrated in hamsters, rats and humans [11-13]. AVNs exhibit antioxidant, anti-inflammatory and anti-irritant activities in vitro and in vivo [14] and anti-proliferative properties, in vitro [15].

Apoptosis is a specific mechanism of cell death, which regulates tissue homeostasis, through the elimination of potentially deleterious cells [16]. Apoptosis is controlled by two pathways: the intrinsic pathway is regulated by the initiator caspase 9 , leading to activation of executioner caspase 3 ; the extrinsic pathway is triggered by the interaction of the death ligand with its death receptor, leading to activation of initiator caspase 8 and then of caspase 3 [17].

The apoptotic program is controlled by a family of proteins called Inhibitor of Apoptosis Proteins (IAPs). Survivin, codified by the gene BIRC5, is a member of the IAPs family, that acts as a suppressor of apoptosis, through the inhibition of cleavage and activation of caspase 9 [18]. Survivin is over-expressed in several human neoplasms and it is currently used as a prognostic marker [19].

Other important factors, which control the survival of over-proliferating tumor cells, are the genes involved in angiogenesis and tumor progression [20]. These genes are mostly regulated by hypoxia inducible factors (HIFs) [21, 22]. HIFs are heterodimers of two subunits: the constitutively expressed HIF $1 \beta$ and the oxygen responsive HIF1 $\alpha$; the latter is codified by the gene HIF1A [23]. HIF1A plays an oncogenic role in colorectal cancer, since its overexpression has been associated with higher mortality rate and shorter survival [24]. 
The protein HIF1 $\alpha$ controls the expression of several genes, such as VEGFA, which encodes for Vascular Endothelial Growth Factor (VEGF), the principal regulator of angiogenesis during tumor growth [25, 26]. VEGF is also able to inhibit apoptosis through up-regulation of IAPs [27].

CaCo-2 colon cancer cells are characterized by a mutated TP53 gene and overexpression of anti-apoptotic factors, which confer resistance to anticancer drugs [28]. HepG2 liver cancer cells are characterized by a wild type TP53 gene and mutations in the tumor suppressor gene Cyclin-Dependent Kinase inhibitor 2A [29], which confer high resistance to apoptosis induction [30]. From a pathophysiological point of view, colorectal carcinoma and hepatocarcinoma are linked, because the colorectal cancer is able to invade the primary tissue and generate liver metastases [31]. Therefore a drug, which shows remarkable activity against both cancer types, is relevant for chemoprevention.

This study was undertaken to set up the purification method of AVNs from oat sprouts, in order to test the antiproliferative effect of the AVNs+XVX combination on both CaCo-2 and HepG2 cancer cell lines. The mechanisms by which these phytochemicals induce apoptosis and downregulate the cancer cell pro-survival mechanisms were investigated as well.

\section{Materials and methods}

\section{Reagents and chemicals}

Ethanol and ethyl-acetate (analytical grade) were purchased from VWR International (Radnor, USA). DMEM culture medium, fetal bovine serum (FBS), antibiotics, trypsin, MEM non-essential amino acid solution, Sulforhodamine B sodium salt, water (LC-MS grade), acetonitrile (LC-MS grade), formic acid (LC-MS grade), glacial acetic acid, 2,2'Azobis (2-amidinopropane) dihydrocloride (AAPH), 6-hydroxy-2,5,7,8-tetramethylchroman 2-carboxylic acid (Trolox), Fluorescein, $\mathrm{H}_{2} \mathrm{O}_{2}$, HBSS-- (without calcium and magnesium) and DCFH-DA were purchased from Sigma-Aldrich (St. Louis, USA).

\section{AVN purification}

\section{Oat sprouting}

Oat grains, provided by the local producer Terra Bio Soc. Coop. (Urbino, Italy), were steeped and germinated for 14 and 72 hours, respectively, using an automatic sprouter (Fresh Life 2000, Corrupad Korea Co. Ltd., Korea), following the methods previously reported $[9,10]$. Steeped and germinated oat grains were freeze-dried and stored at $-20^{\circ} \mathrm{C}$ until analysis. Samples were milled in a ZM 200 ultracentrifugal mill with a 0.5 ring sieve (Retsch, Haan, Germany).

\section{Extraction and isolation of AVNs}

AVNs were extracted from milled oat with acidified ethanol (1:10 w/v), following the procedure reported by us [8], with the exception that ethanol was acidified with $0.1 \%$ glacial acetic acid, instead of $10 \mathrm{mM} \mathrm{H}_{3} \mathrm{PO}_{4}$ buffer. 
The raw extract was concentrated by rotary evaporation to $1 / 10$ of the initial volume. To remove lipophilic components from the extract, we followed the procedure reported by Liu et al [32], with some modifications. Briefly, Octyl Sepharose $^{\mathrm{TM}}$ CL 4-B (GE Healthcare Bio-Sciences AB, Uppsala, Sweden) was added to the extract (0.5 ml per $\mathrm{g}$ extracted). The mixture was completely dried, re-suspended in acidified $50 \%$ ethanol and transferred to a glass chromatography column containing Octyl Sepharose ${ }^{\mathrm{TM}}$ CL 4-B, previously pre-equilibrated in acidified $50 \%$ ethanol. The column was then eluted with $3 \times$ bed volume $\left(\mathrm{V}_{\mathrm{b}}\right)$ of acidified $50 \%$ ethanol. The eluate was concentrated under vacuum, at $40^{\circ} \mathrm{C}$, by rotary evaporation.

The defatted dried extract was dissolved in acidified 30\% ethanol and purified on a Sephadex LH-20 column (50 x 150 mm; Sigma-Aldrich Inc., St. Louis, USA), equilibrated in acidified $30 \%$ ethanol, and controlled by the LCChromatograph AKTA Purifier 10 (GE Healthcare Bio-Sciences AB, Uppsala, Sweden). The mobile phase was changed as follows: $2 \mathrm{x} \mathrm{Vb}$ of acidified 30\% ethanol in isocratic mode to remove amino acids, free sugars, proteins, etc. [32]; $2 \times \mathrm{Vb}$ of acidified $50 \%$ ethanol in isocratic mode to remove the flavonoids and phenolic acids [32]; $2 \times \mathrm{Vb}$ of acidified ethanol from 50 to $95 \%$ in gradient mode, to recover the absorbed AVNs. The flow rate was $5 \mathrm{ml} / \mathrm{min}$ and absorbance values were obtained at $330 \mathrm{~nm}$.

\section{HPLC-PDA-MS analysis of AVNs}

The dried fractions obtained from the Sephadex LH-20 column chromatography were dissolved in ethanol and directly analyzed in a Water instrument equipped with Alliance HT 2795 High Performance liquid Chromatography (HPLC), 2996 Photo Diode Array (PDA) and Micromass LC/MS ZQ 2000 detector, following the procedure reported by us [8].

To identify the individual AVNs in the HPLC chromatograms, retention time, UV spectra, MS ESI (+) and ESI (-) spectra were compared with those of commercially available external standards (AVN A, B, C, Sigma-Aldrich, St. Louis, USA), and the peak areas were used for quantification.

XVX was isolated from seeds of BVc, obtained from Suba Seeds Company S.p.A. (Longiano, Italy). The extract from seeds was prepared by solid-liquid extraction with $70 \%$ ethanol in a Timatic extractor (Tecnolab S.r.l., Spello, Italy) and liquid-liquid extraction with ethyl-acetate. Two chromatography columns were applied: a Diaion HP-20 (SigmaAldrich, St. Louis, USA) and a Davisil C18 (ALLTECH, Milan, Italy), performed by means of the LC-Chromatograph AKTA Purifier 10, following the elution of XVX at $336 \mathrm{~nm}$ [3].

The HPLC analysis of XVX was performed using the same HPLC equipment used for AVNs, but a spherisorb ODS2 column (4.6 x $250 \mathrm{~mm}$; Waters Corporation, Milford, USA), with $5 \mu \mathrm{m}$ particle size was used. Standard and sample injected volumes were $20 \mu \mathrm{l}$. The gradient consisted of $0.01 \%$ acetic acid in water (solvent A) and methanol containing 
$0.01 \%$ acetic acid (solvent $\mathrm{B}$ ), developed as follows: from 0 to $60 \%$ solvent $\mathrm{B}$ in the interval $0-45 \mathrm{~min}$ at $1 \mathrm{ml} / \mathrm{min}$, then to $100 \% \mathrm{~B}$ in the interval $45-50 \mathrm{~min}$. XVX was identified using a purified standard available in our lab [3].

\section{ORAC Assay}

Antioxidant activity was assessed using the ORAC (Oxygen Radical Absorbance Capacity) assay and a Fluostar Optima plate reader fluorimeter (BMG Labtech, Offenburgh, Germany) equipped with a temperature-controlled incubation chamber and automatic injection pump according to Ninfali et al [33]. Fluorescence was read at $485 \mathrm{~nm}$ ex. and $520 \mathrm{~nm}$ em. until complete extinction. ORAC values were expressed as $\mu$ mol Trolox Equivalents (TE) $\mathrm{g}^{-1} \mathrm{~d}$.m, which was used as external standard.

\section{Cell cultures}

HepG2 liver cancer cell line and CaCo-2 colon cancer cell line were purchased from the American Type Culture Collection (ATCC, Rockville, USA) and maintained in DMEM supplemented with 10\% FBS, 2 mM glutamine, 100 $\mathrm{U} / \mathrm{ml}$ penicillin, $100 \mu \mathrm{g} / \mathrm{ml}$ streptomycin and $100 \mu \mathrm{M}$ MEM non-essential amino acid solution. NCTC 2544 normal human keratinocytes were obtained from Interlab Cell Line Collection (ICLC, Genova, Italy) and maintained in DMEM supplemented with $10 \% \mathrm{FBS}, 2 \mathrm{mM}$ glutamine, $100 \mathrm{U} / \mathrm{ml}$ penicillin, $100 \mu \mathrm{g} / \mathrm{ml}$ streptomycin. Cell lines were grown at $37^{\circ} \mathrm{C}$ in a humidified atmosphere with $5 \% \mathrm{CO}_{2}$.

\section{Sulforhodamine B (SRB) assay}

Cells $\left(10^{4} /\right.$ well for CaCo-2 and NCTC 2544; 2x104/well for HepG2) were plated in 96-well plates and treated with XVX and AVNs, both individually and in combination, for 24, 48 and 72 hours. At the end of treatment, cells were incubated with SRB as previously reported [5]. The results were expressed as the percentage of cell viability, compared to control untreated cells (100\% viability).

\section{DCFH-DA assay for Cellular Antioxidant Capacity (CAA) evaluation}

Cells were seeded $\left(2 \times 10^{5}\right.$ for CaCo-2 and $3 \times 10^{5}$ for HepG2) in 6-well plates and treated for $24 \mathrm{~h}$ with P4 or P3. After removing of cell medium, the production of ROS in CaCo-2 and HepG2 cells was monitored following the procedure reported by Farabegoli et al [5], with the substitution of PBS with HBSS -- only. After incubation, the cells were observed at microscope with a green FITC filter (OLYMPUS IX51). Cells showing a bright and intense green fluorescence were counted as positive, whereas cells with no or low fluorescence were counted as negative. Three fields per sample were analyzed and each time at least 100 cells were counted. Three independent experiments were performed for both CaCo-2 and HepG2 cells and results were expressed as \% DCF fluorescent positive cells versus control. The images were obtained using the software OLYMPUS Ps-blm1.

Determination of caspase 3, caspase 9 and caspase 8 activities 


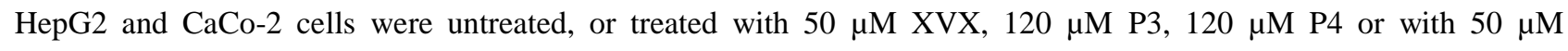
$\mathrm{XVX}+120 \mu \mathrm{M}$ P4 for $48 \mathrm{~h}$, then the Petri dishes were put in ice and the cytosols were extracted following the procedure previously reported [34].

Caspase 3, caspase 9 and caspase 8 activities were assessed through the Caspase Colorimetric Assay Kit (BioVision, Milpitas, USA) according to the manufacturer's instructions. $100 \mu \mathrm{g}$ of cytosol from untreated or phytochemicals treated HepG2 and CaCo-2 cells were incubated with caspase reaction buffer $(25 \mathrm{mM}$ Hepes $\mathrm{pH} 7.4,50 \mathrm{mM} \mathrm{NaCl}$, 0.05\% CHAPS, $0.5 \mathrm{mM}$ EDTA, 5\% glycerol, $5 \mathrm{mM}$ DTT), then the substrate (200 $\mu$ M final concentration) DMQDpNA specific for caspase 3, or LEHD-pNA specific for caspase 9, or IETD-pNA specific for caspase 8 was added and the samples were transferred in a 96-wells microplate. All samples were incubated at $37^{\circ} \mathrm{C}$ for $2 \mathrm{~h}$. The absorbance, representing the activities of caspases, was measured at $\lambda=405 \mathrm{~nm}$ in a microplate reader (BioRad Laboratories, Hercules, USA).

\section{RNA extraction, cDNA production and RTqPCR experiments}

Total RNA was extracted from CaCo-2 and HepG2 cells using the TriReagent (Invitrogen, Carlsbad, USA), following the manufacturer's protocol. cDNA production and RTqPCR assays were performed as previously reported [34]. The following list of primers was used: $\beta$-Actin F: 5'-GCGAGAAGATGACCCAGATC-3' , R: 5'-

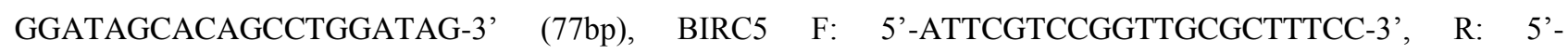
CACGGCGCACTTTCTCCGCAG-3'(162bp), HIF1A F: 5'-TCTGGGTTGAAACTCAAGCAACTG-3', R: 5'CAACCGGTtTAAGGACACATTCTG-3' (150 bp), VEGFA F: 5'-TCACAGGTACAGGGATGAGGACAC-3', R: 5'-CAAAGCACAGCAATGTCCTGAAG-3' (72 bp).

Statistical analysis

Data were expressed as mean \pm SD. Statistical significance was assessed by one-way ANOVA, using PRISM 5.1 (GraphPad Software, La Jolla, USA). The results were considered statistically significant when $p<0.05$.

\section{Results}

\section{Purification of AVNs}

AVNs were purified from oat sprouts, using the Sephadex LH-20 column chromatography. We obtained four main peaks, labeled as P1-P4 (Fig. 1a). The HPLC-PDA-MS analysis revealed that P1 and P2 peaks, contained hydrophilic contaminants and were discarded; P3 and P4, both containing AVNs, were collected and concentrated to dryness. From the HPLC-PDA-MS analysis, P3 revealed the presence of AVN B only, at 95\% purity level (Fig. 1b); P4 revealed the presence of a mixture of AVN A, B, C, representing $80 \%$ of the whole weight (Fig. 1c). The structural formulae are shown in Fig. $1 \mathrm{~b}$ and $1 \mathrm{c}$. The relative $\%$ ratios of the AVN A, B, C of P4 are reported in Table 1. The concentrations 
were accurately evaluated by HPLC, referring to calibration curves made with commercial AVN A, B, C standards. The remaining $20 \%$ of the $\mathrm{P} 4$ fraction was characterized by minor AVN forms (Fig. 1c; peaks 1-4), which were quantified using the commercial AVN A as external standard [32]. Our protocol for the chromatographic purification of AVN forms gave a reproducible profile in several repeated experiments $(n=3)$. Our profile slightly differs from those of other authors [32]. It is worth to remember here that in the presentation of the following results, we used the label P3 for AVN B and P4 for the AVN mixture (AVN A, B, C).

\section{Antioxidant capacity evaluation}

The antioxidant capacity, evaluated through the ORAC method, showed ORAC values of 6,547 \pm 290 and $19,079 \pm 474$ $\mu \mathrm{mol} \mathrm{TE} / \mathrm{g}$ for P3 and P4, respectively (Table 1). The higher ORAC value of the P4 fraction should be related to the presence of AVN C, which is considered the most potent antioxidant form [35].

\section{Purification of XVX}

XVX was purified in our laboratory from BVc seeds at $95 \%$ purity level. The XVX powder, stored at $-20 \mathrm{C}$, was used alone or in combination with AVNs for cell treatments. The purification protocol was tested along several years of reproducible experiments [3].

\section{Antiproliferative effects of individual phytochemicals}

Earlier studies on normal human cells allowed us to choose the concentration range of XVX, P3 and P4 to be used in the dose response experiments of antiproliferative activity. As no cytotoxic effects were detected by us when XVX was used in the range $0-100 \mu \mathrm{M}$ and when AVNs were used in the range 0-120 $\mu \mathrm{M}$ on normal NCTC 2544 cells (Online resource 1), we planned to evaluate antiproliferative effects on $\mathrm{CaCo}-2$ and $\mathrm{HepG} 2$ cancer cells in this concentration range for XVX and for $\mathrm{P} 3$ and $\mathrm{P} 4$.

Fig. 2 shows the antiproliferative effects on CaCo-2 colon cancer cells (a, c, e) and HepG2 liver cancer cells (b, d, f) of the individual phytochemicals at $48 \mathrm{~h}$. At this treatment time, the maximum antiproliferative effect occurred.

On CaCo-2 cells, the $\mathrm{IC}_{50}$ values, at $48 \mathrm{~h}$ were: $50.9 \pm 5.5 \mu \mathrm{M}, 126.5 \pm 12.5 \mu \mathrm{M}, 114.6 \pm 5.5 \mu \mathrm{M}$, for XVX, P3 and P4 respectively. Otherwise, on $\mathrm{HepG} 2$ cells, the $\mathrm{IC}_{50}$ values, at $48 \mathrm{~h}$ were: $71.6 \pm 7.4 \mu \mathrm{M}, 182.7 \pm 18.1 \mu \mathrm{M}, 39.9 \pm 4.1 \mu \mathrm{M}$ for XVX, P3 and P4 respectively. Therefore, the XVX treatment was the most cytotoxic on CaCo-2 cells, while the P4 treatment was the most cytotoxic on HepG2 cells.

\section{Modulation of the caspase activities by individual phytochemicals}

XVX, P3 and P4 were used to investigate, at $48 \mathrm{~h}$, the ability of these phytochemicals to activate both the initiator caspases 8 and 9 and the effector caspase 3 in CaCo-2 and HepG2 cancer cells (Fig. 3).

The caspase 3 activity significantly increased on both CaCo-2 (Fig. 3a) and HepG2 (Fig. 3b) cancer cells with P4 and XVX treatments; otherwise, P3 was effective in CaCo-2 cells only. 
The caspase 9 activity, linked to the "intrinsic" pathway of apoptosis, increased in the presence of XVX, but not in the presence of P4 or P3, on both CaCo-2 (Fig. 3c) and HepG2 (Fig. 3d) cancer cell lines.

In $\mathrm{CaCo}-2$ cells, the caspase 8 activity, linked to the "extrinsic" apoptotic pathway, significantly increased in the presence of P4 and P3, but not in the presence of XVX (Fig. 3e); otherwise in HepG2 cells, only P4 was able to induce a significant increase in caspase 8 activity levels (Fig. 3f). In other words, XVX activates the intrinsic apoptotic pathway, while AVNs activate the extrinsic apoptotic pathway, in both colon and liver cancer cells (Fig. 3).

\section{Cellular antioxidant activity (CAA) of P4 and P3}

We incubated the CaCo-2 and HepG2 cells with P3 and P4, individually, in order to test their CAA, which is also an indication of the permeability of the phytochemicals through the cell membranes. The CaCo-2 cells (Fig. 4a) were treated for 24h with $60 \mu \mathrm{M} \mathrm{P} 4$ and $60 \mu \mathrm{M} \mathrm{P}$, whereas the HepG2 cells (Fig. 4b) with $30 \mu \mathrm{M} \mathrm{P4}$ and $120 \mu \mathrm{M} \mathrm{P3}$, before generating ROS by $1 \mathrm{mM} \mathrm{H}_{2} \mathrm{O}_{2}$ for $1 \mathrm{~h}$. The choice of $\mathrm{P} 4$ and $\mathrm{P} 3$ concentrations was based on the minimum phytochemical concentration that showed a statistically significant antiproliferative effect on CaCo-2 and $\mathrm{HepG} 2$ cancer cells (Fig. 2).

P4 exerted a stronger CAA than P3 in both CaCo-2 (Fig. 4c) and HepG2 (Fig. 4d) cells, remarkably reducing the number of green fluorescent cells, after treatment with $\mathrm{H}_{2} \mathrm{O}_{2}$. These results suggest a link between the AVNs CAA and their antiproliferative effects on CaCo-2 and HepG2 cancer cells. $[4,36]$.

\section{Molecular effects of the XVX+P4 mixture}

P4 only was chosen to be tested for the antiproliferative activity in combination with XVX. This choice was due to its lower $\mathrm{IC}_{50}$ value, to the greater induction in caspase 8 and caspase 3 activity levels and to the higher CAA exerted in both cancer cell lines, when compared to P3.

CaCo-2 and HepG2 cells were incubated for $48 \mathrm{~h}$ with XVX maintained at $50 \mu \mathrm{M}$ and $\mathrm{P} 4$ at the increasing concentrations of 30,60 or $120 \mu \mathrm{M}$. The combination $50 \mu \mathrm{M}$ XVX+120 $\mu \mathrm{M}$ P4 showed the greatest antiproliferative effects on both cancer cell lines (Fig. 5a, 5b) and induced also the highest increase in the activity levels of caspase 3, 9 and 8 in both CaCo-2 and HepG2 cancer cell lines (Table 2).

XVX+P4 mediated downregulation of BIRC5, HIF1A and VEGFA expression levels

Through RTqPCR assays, we assessed whether XVX and P4, used alone and in combination, were able to reduce the expression levels of the pro-survival genes BIRC5, HIF1A and VEGFA in CaCo-2 and HepG2 cancer cells. 
Our results (Fig. 6) showed a downregulation of the expression levels of the anti-apoptotic gene BIRC5 (survivin) by XVX and XVX+P4 on CaCo-2 (Fig. 6a) and HepG2 (Fig. 6b) cells. The treatment with P4 alone was ineffective on both cancer cell lines (Fig. 6a, 6b). Individually, XVX and P4 were able to significantly downregulate the expression levels of HIF1A on both CaCo-2 (Fig. 6c) and HepG2 (Fig. 6d) cancer cells. In addition, $\mathrm{XVX}+\mathrm{P} 4$ showed a remarkable reduction $(\mathrm{p}<0.001)$ in HIF1A expression levels in both cancer cell lines (Fig. 6c, 6d).

XVX and P4, used alone, were also able to decrease the expression levels of VEGFA on both CaCo-2 (Fig. 6e) and HepG2 (Fig. 6f) cancer cells. The combination XVX+P4 showed a remarkable downregulation of the expression levels of VEGFA, with a greater extent on HepG2 than on CaCo-2 cells (Fig. 6e and 6f). In synthesis, XVX and P4 (AVNs), much better in combination than alone, markedly downregulated the expression levels of the genes HIF1A and VEGFA on both cancer cell lines, confirming data obtained with other flavonoids [37].

\section{Discussion}

The phytochemicals XVX and AVNs are purified in our lab from Beta vulgaris var cicla L. and Avena sativa L., respectively. Green beet and oat are foods widely consumed in the Western and Eastern countries. With the ingestion of these foods, the above nutrients are absorbed in the gut and reach the liver through entero-hepatic recirculation [38]. By this way, these phytochemicals are bioavailable and able to exploit their biological effects in both colon and liver cells [38].

When a tumor develops in the colon, the cancer cells may spread into the liver and metastatize there [31]. Therefore, a couple of phytochemicals able to exploit biological effects on both colon and liver tissues, represent an important chemopreventive tool for subjects exposed to colon cancer risks, such as hereditary adenomatous polyposis [31]. In our study, we have evaluated the antiproliferative effects of a combination of XVX and AVNs, in an in vitro model of colon and liver cancer cell lines. Our results showed that XVX and AVNs, used individually, were able to inhibit the proliferation of both CaCo-2 and HepG2 cancer cells, without inducing cytotoxic effects on normal human NCTC 2544 cells. Regarding the two AVN fractions that we isolated, P4 (AVNs mix) was more active as an antiproliferative agent, than P3 (AVN B). This may be explained by a synergy among the AVN A, B, C forms contained in P4, an hypothesis which is sustained by the higher ORAC and CAA of P4, compared to P3.

Our results also demonstrated that the combination XVX+AVNs mix (P4) showed a greater inhibition of proliferation rate than XVX and AVNs used alone. This antiproliferative effect was exerted through the ability of the XVX+AVNs to activate both intrinsic and extrinsic apoptotic pathways. In fact, caspase 3 activity was increased to a greater extent by $\mathrm{XVX}+\mathrm{AVNs}$ than by the individual compounds, in both cancer cell lines. It has already been shown that XVX exerts its 
anticancer effect through the activation of the effector caspase 3 in several cancer cell lines [5, 34], but this is the first time that such a remarkable increase in caspase 3 activity was identified in the presence of the couple XVX+AVNs in CaCo-2 and HepG2 cancer cell lines.

Another interesting aspect of this report was the effect exerted by our phytochemicals on the modulation of some genes, which are fundamental for cancer cell survival.

In fact, our data showed that the XVX+AVNs combination remarkably reduced the expression levels of the pro-survival factors: BIRC5, HIF1A and VEGFA. The rationale for the choice of these genes among the many others possible markers, in this research, derived from previous works, showing that XVX downregulated BIRC5 in T24 bladder cancer cells [34], and vitexin, the mono glucoside of apigenin, was able to decrease the activity of HIF1 $\alpha$ and downregulate the capacity of the XVX+AVNs combination to reduce the anti-apoptotic defenses of the CaCo-2 and HepG2 cancer cell lines, influencing the expression of the members of the IAPs family, in which survivin, the BIRC5 gene product, is enclosed [40].

Notably, XVX treatment was the most cytotoxic on CaCo-2 cells, while the AVNs treatment was the most cytotoxic on HepG2 cells, but when utilized in the mixture, the antiproliferative effect of XVX+AVNs combination was greater in HepG2 than in CaCo-2 cells. We hypothesized that this different behavior could be linked to the different genetic background of the two cancer cell lines, as CaCo-2 cells possess a mutated TP53 gene, whereas HepG2 cells a wild type TP53 gene. We believe that in HepG2 cells, the p53 protein levels could be increased by the phytochemical combination, leading to activation of apoptosis, as it was demonstrated by others for all-trans retinoic acid [29]. However, the clarification of this aspect deserves further research.

In conclusion, our work shows that the combined action of XVX and AVNs (P4) induces both intrinsic and extrinsic apoptotic pathways on CaCo-2 and HepG2 cancer cells, as well as by the downregulation of the pro-survival factors BIRC5, HIF1A and VEGFA in both cancer cell lines.

$\mathrm{XVX}$ and AVNs derive from renewable vegetable sources and their purification can be scaled up for a wider request of these phytochemicals for nutraceutical preparations, as the synthesis of these molecules is difficult, expensive and, for $\mathrm{XVX}$, not fully feasible. Our in vitro study creates the basis for the possible use of this combined treatment for chemoprevention against the insurgence of both colon and liver cancers also in vivo.

Conflict of Interest On behalf of all authors, the corresponding author states that there is no conflict of interest.

\section{Abbreviations}


307

AVNs, avenanthramides

BIRC5, Baculoviral Inhibitor of apoptosis Repeat-Containing 5

BVc, Beta vulgaris var. cicla $\mathrm{L}$.

CAA, Cellular Antioxidant Activity

DCFH-DA, 2', 7'-dichlorodihydrofluorescein diacetate

HIF1A, Hypoxia Inducible Factor 1A

HPLC, High Pressure Liquid Chromatography

IAPs, Inhibitor of Apoptosis Proteins

MS, Mass Spectrometry

ORAC, Oxygen Radical Absorbance Capacity

PDA Photo Diode Array

SRB, Sulforhodamine B

UV, Ultraviolet

VEGF, Vascular Endothelial Growth Factor

XVX, vitexin-2-O-xyloside

\section{References}

1. Ninfali P, Bacchiocca M, Antonelli A, Biagiotti E, Di Gioacchino AM, Piccoli G, Stocchi V, Brandi G (2007) Characterization and biological activity of the main flavonoids from Swiss Chard (Beta vulgaris subspecies cycla). Phytomedicine 14:216-221

2. Ninfali P, Angelino D (2013) Nutritional and functional potential of Beta vulgaris cicla and rubra. Fitoterapia 89:188-199

3. Gennari L, Felletti M, Blasa M, Angelino D, Celeghini C, Corallini A, Ninfali P (2011) Total Extract of Beta Vulgaris Var. Cicla Seeds versus Its Purified Phenolic Components: Antioxidant Activities and Antiproliferative Effects Against Colon Cancer Cells. Phytochem Analysis 22:272-279

4. Papi A, Farabegoli F, Iori R, Orlandi M, De Nicola GR, Bagatta M, Angelino D, Gennari L, Ninfali P (2013) Vitexin-2-0-xyloside, raphasatin and (-)-epigallocatechin-3-gallate synergistically affect cell growth and apoptosis of colon cancer cells. Food Chem 138:1521-1530 
5. Farabegoli F, Scarpa ES, Frati A, Serafini G, Papi A, Spisni E, Antonini E, Benedetti S, Ninfali P (2017) Betalains increase vitexin-2-O-xyloside cytotoxicity in CaCo-2 cancer cells. Food Chem 218:356-364

6. Peterson DM (2001) Oat antioxidants. J Cereal Sci 33:115-129

7. Collins FW (1989) Oat phenolics: avenanthramides, novel substituted N-cinnamoylanthranilate alkaloids from oat groats and hulls. J Agr Food Chem 37:60-66

8. Antonini E, Lombardi F, Alfieri M, Diamantini G, Redaelli R, Ninfali P (2016) Nutritional characterization of naked and dehulled oat cultivar samples at harvest and after storage. J Cereal Sci 72:46-53

9. Skoglund M, Peterson DM, Andersson R, Nilsson J, Dimberg LH (2008) Avenanthramide content and related enzyme activities in oats as affected by steeping and germination. J Cereal Sci 48:294-303

10. Xu JG, Tian CR, Hu QP, Luo JY, Wang XD, Tian XD (2009) Dynamic changes in phenolic compounds and antioxidant activity in oats (Avena nuda L.) during steeping and germination. J Agr Food Chem 57:10392-10398

11. Chen CY, Milbury PE, Kwak HK, Collins FW, Samuel P, Blumberg JB (2004) Avenanthramides and phenolic acids from oats are bioavailable and act synergistically with vitamin $\mathrm{C}$ to enhance hamster and human LDL resistance to oxidation. J Nutr 134:1459-1466

12. Chen CYO, Milbury PE, Collins FW, Blumberg JB (2007) Avenanthramides are bioavailable and have antioxidant activity in humans after acute consumption of an enriched mixture from oats. J Nutr 137:13751382

13. Koenig RT, Dickman JR, Wise ML, Ji LL (2011) Avenanthramides Are Bioavailable and Accumulate in Hepatic, Cardiac, and Skeletal Muscle Tissue Following Oral Gavage in Rats. J Agr Food Chem 59:64386443

14. Meydani M (2009) Potential health benefits of avenanthramides of oats. Nutr Rev 67:731-735

15. Guo WM, Nie L, Wu DY, Wise ML, Collins FW, Meydani SN, Meydani M (2010) Avenanthramides Inhibit Proliferation of Human Colon Cancer Cell Lines In Vitro. Nutr Cancer 62:1007-1016

16. Holdenrieder S, Stieber P (2004) Apoptotic markers in cancer. Clin Biochem 37:605-617 
17. Samali A, Jager R (2014) Mechanisms of resistance to cell death pathways in cancer cells. In: McManus LM, Mitchell RN (eds) Pathobiology of Human Disease, 1st edn. Elsevier Inc., Atlanta, pp 393-402

19. Johnson ME, Howerth EW (2004) Survivin: A bifunctional inhibitor of apoptosis protein. Vet Pathol 41:599-607

20. Hanahan D, Weinberg RA (2011) Hallmarks of cancer: the next generation. Cell 144:646-674

21. Gomez-Roman N, Sahasrabudhe NM, McGregor F, Chalmers AJ, Cassidy J, Plumb J (2016) Hypoxiainducible factor 1 alpha is required for the tumourigenic and aggressive phenotype associated with Rab25 expression in ovarian cancer. Oncotarget 7:22650-22664

23. Wang GL, Jiang BH, Rue EA, Semenza GL (1995) Hypoxia-Inducible Factor-1 Is A Basic-Helix-LoopHelix-Pas Heterodimer Regulated by Cellular O-2 Tension. P Natl Acad Sci USA 92:5510-5514

24. Baba Y, Nosho K, Shima K, Irahara N, Chan AT, Meyerhardt JA, Chung DC, Giovannucci EL, Fuchs CS, Ogino S (2010) HIF1A overexpression is associated with poor prognosis in a cohort of 731 colorectal cancers. Am J Pathol 176:2292-2301

25. Ferrara N (2005) VEGF as a therapeutic target in cancer. Oncology 69:11-16

26. Ellis LM, Takahashi Y, Liu W, Shaheen RM (2000) Vascular endothelial growth factor in human colon cancer: biology and therapeutic implications. Oncologist 5:11-15

27. Doll JA, Hobbs JE, Soff JA (2007) Role of apoptosis in anti-angiogenic cancer therapies. In: Gewirtz DA, Holt SE, Grant S (eds) Apoptosis and Senescence in Cancer Chemotherapy and Radiotherapy, 2nd edn. Humana Press, Totowa, pp 537-555

28. Piccirillo S, Filomeni G, Brune B, Rotilio G, Ciriolo MR (2009) Redox Mechanisms Involved in the Selective Activation of Nrf2-mediated Resistance Versus p53-dependent Apoptosis in Adenocarcinoma Cells. J Biol Chem 284:27721-27733 
29. Heo SH, Kwak J, Jang KL (2015) All-trans retinoic acid induces p53-depenent apoptosis in human hepatocytes by activating p14 expression via promoter hypomethylation. Cancer Lett 362:139-148

386

30. Ye RP Chen ZD (2016) Saikosaponin A, an active glycoside from Radix bupleuri, reverses P-glycoproteinmediated multidrug resistance in MCF-7/ADR cells and HepG2/ADM cells. Xenobiotica 1-9

31. Ferlay J, Autier P, Boniol M, Heanue M, Colombet M, Boyle P (2007) Estimates of the cancer incidence and mortality in Europe in 2006. Ann Oncol 18:581-592

32. Liu LP, Zubik L, Collins FW, Marko M, Meydani M (2004) The antiatherogenic potential of oat phenolic compounds. Atherosclerosis 175:39-49

33. Ninfali P, Gennari L, Biagiotti E, Cangi F, Mattoli L, Maidecchi A (2009) Improvement in botanical standardization of commercial freeze-dried herbal extracts by using the combination of antioxidant capacity and constituent marker concentrations. J AOAC Int 92:797-805

34. Scarpa ES, Emanuelli M, Frati A, Pozzi V, Antonini E, Diamantini G, Di RG, Sartini D, Armeni T, Palma F, Ninfali P (2016) Betacyanins enhance vitexin-2-O-xyloside mediated inhibition of proliferation of T24 bladder cancer cells. Food Funct. doi:10.1039/c6fo01130f

35. Peterson DM, Hahn MJ, Emmons CL (2002) Oat avenanthramides exhibit antioxidant activities in vitro. Food Chem 79:473-478

36. Blasa M, Angelino D, Gennari L, Ninfali P (2011) The cellular antioxidant activity in red blood cells (CAA-RBC): A new approach to bioavailability and synergy of phytochemicals and botanical extracts. Food Chem 125:685-691

37. Huang H, Chen AY, Rojanasakul Y, Ye X, Rankin GO, Chen YC (2015) Dietary compounds galangin and myricetin suppress ovarian cancer cell angiogenesis. J Funct Foods 15:464-475

38. Angelino D, Berhow M, Ninfali P, Jeffery EH (2013) Caecal absorption of vitexin-2-O-xyloside and its aglycone apigenin, in the rat. Food Funct 4:1339-1345

39. Choi HJ, Eun JS, Kim BG, Kim SY, Jeon H, Soh Y (2006) Vitexin, an HIF-1alpha inhibitor, has antimetastatic potential in PC12 cells. Mol Cells 22:291-299 
409 40. Ma J, Feng Y, Liu Y, Li X (2016) PUMA and survivin are involved in the apoptosis of HepG2 cells 410 induced by microcystin-LR via mitochondria-mediated pathway. Chemosphere 157:241-249 
413 Fig. 1 Elution profile showing the four main peaks (P1-P4) obtained from the Sephadex LH-20 column chromatography loaded with the extract of milled oat (a); HPLC profile of P3 (b) and P4 (c), used for the cytotoxicity assays. P3 contains the AVN B (B); P4 contains a mixture of peaks, corresponding to AVN C (C), AVN A (A), AVN B (B) and other minor AVNs (peaks 1-4). The structural formulae are also shown

Fig. 2 The antiproliferative effects of P3, P4 and XVX on CaCo-2 colon cancer cells (a, c, e) and HepG2 liver cancer cells (b, d, f), after $48 \mathrm{~h}$ treatment. Data were expressed as percentage of cell viability relative to the control, represented by the corresponding untreated cells. Three replicate experiments with three samples analyzed for each replicate $(\mathrm{n}=9)$ were performed $* \mathrm{p}<0.05, * * \mathrm{p}<0.01, * * * \mathrm{p}<0.001$

Fig. 3 Evaluation of caspase 3, caspase 9 and caspase 8 activity levels, induced by XVX, P3 and P4 in CaCo-2 (a, c, e, respectively) and HepG2 (b, d, f, respectively) cancer cells. Cells were untreated (CTRL), or treated for 48h with P3 $(120 \mu \mathrm{M})$, or P4 $(120 \mu \mathrm{M})$ or XVX $(50 \mu \mathrm{M})$. Data were expressed as \% caspase $3(\mathrm{a}, \mathrm{b}), \%$ caspase 9 (c, d), \% caspase 8 (e, f) activity levels. Three replicate experiments with two samples analyzed for each replicate $(\mathrm{n}=6)$ were performed. $* \mathrm{p}<0.05, * * \mathrm{p}<0.01, * * * \mathrm{p}<0.001$

Fig. 4 Representative images of DCFH-DA assay in CaCo-2 (a) and in HepG2 (b) cells treated with phytochemicals before $\mathrm{H}_{2} \mathrm{O}_{2}$ treatment. CTRL, untreated cells; $\mathrm{H}_{2} \mathrm{O}_{2}$, cells treated with $1 \mathrm{mM} \mathrm{H}_{2} \mathrm{O}_{2}$ for $1 \mathrm{~h}$; $\mathrm{P} 4$ (60 $\mu \mathrm{M})$, cells treated with $60 \mu \mathrm{M}$ P4 for $24 \mathrm{~h}$ and then with $1 \mathrm{mM} \mathrm{H} \mathrm{O}_{2}$ for $1 \mathrm{~h}$; P3 $(60 \mu \mathrm{M})$, cells treated with $60 \mu \mathrm{M}$ P3 for $24 \mathrm{~h}$ and then with $1 \mathrm{mM} \mathrm{H}_{2} \mathrm{O}_{2}$ for $1 \mathrm{~h}$; P4 $(30 \mu \mathrm{M})$, cells treated with $30 \mu \mathrm{M} \mathrm{P} 4$ for $24 \mathrm{~h}$ and then with 1 mM H $\mathrm{O}_{2}$ for $1 \mathrm{~h}$; P3 $(120 \mu \mathrm{M})$, cells treated with $120 \mu \mathrm{M}$ P3 for $24 \mathrm{~h}$ and then with $1 \mathrm{mM} \mathrm{H}_{2} \mathrm{O}_{2}$ for $1 \mathrm{~h}$ (c, d). Three fields per sample were analyzed and each time at least 100 cells were counted; three independent experiments were performed for both $\mathrm{CaCo}-2$ and HepG2 cancer cells $(\mathrm{n}=9)$ and results were expressed as \% DCF fluorescent positive cells versus control; **p<0.01, ***p $<0.001$

Fig. 5 The antiproliferative effect of $\mathrm{XVX}+\mathrm{P} 4$ combination on $\mathrm{CaCo}-2$ colon cancer cells (a) and HepG2 liver cancer cells (b), after $48 \mathrm{~h}$ treatment. Data were expressed as percentage of cell viability relative to the control, represented by the corresponding untreated cells. Three replicate experiments with three samples analyzed for each replicate $(\mathrm{n}=9)$ were performed $* * \mathrm{p}<0.01, * * * \mathrm{p}<0.001$ and VEGFA expression levels in CaCo-2 (a, c, e) and HepG2 (b, d, f) cancer cells. BIRC5 (a, b), HIF1A (c, 

gene $\beta$-actin. Results obtained from untreated cells (CTRL) and from CaCo-2 and HepG2 cells treated with XVX $(50 \mu \mathrm{M}), \mathrm{P} 4(120 \mu \mathrm{M})$, or XVX+P4 (50 $\mu \mathrm{M} X V X+120 \mu \mathrm{M}$ P4) for 24h, are shown. Three replicate experiments with three samples analyzed for each replicate $(n=9)$ were performed. ${ }^{*} \mathrm{p}<0.05,{ }^{*} \mathrm{p}<0.01$, 
b

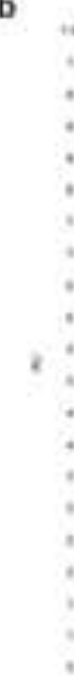

a
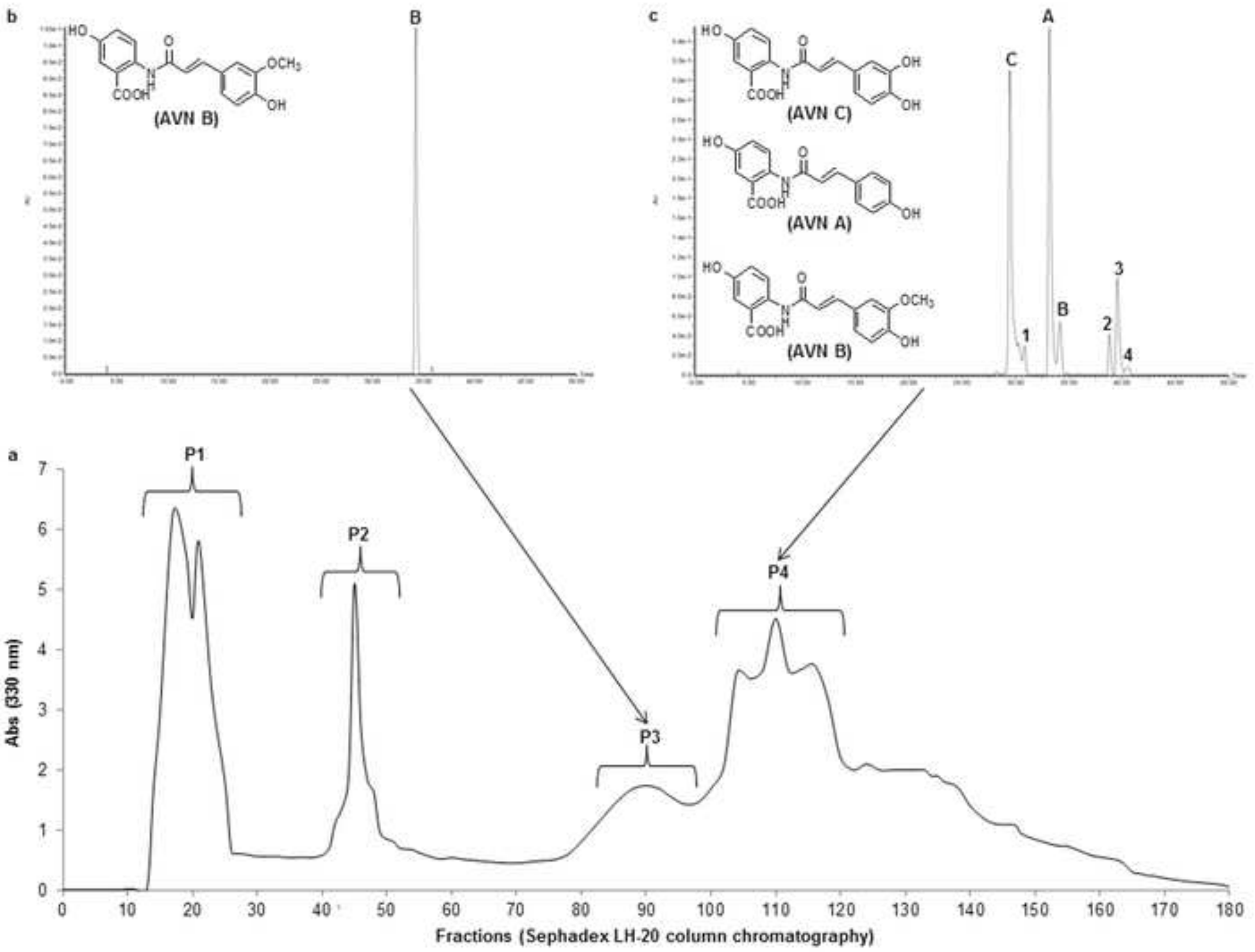

c

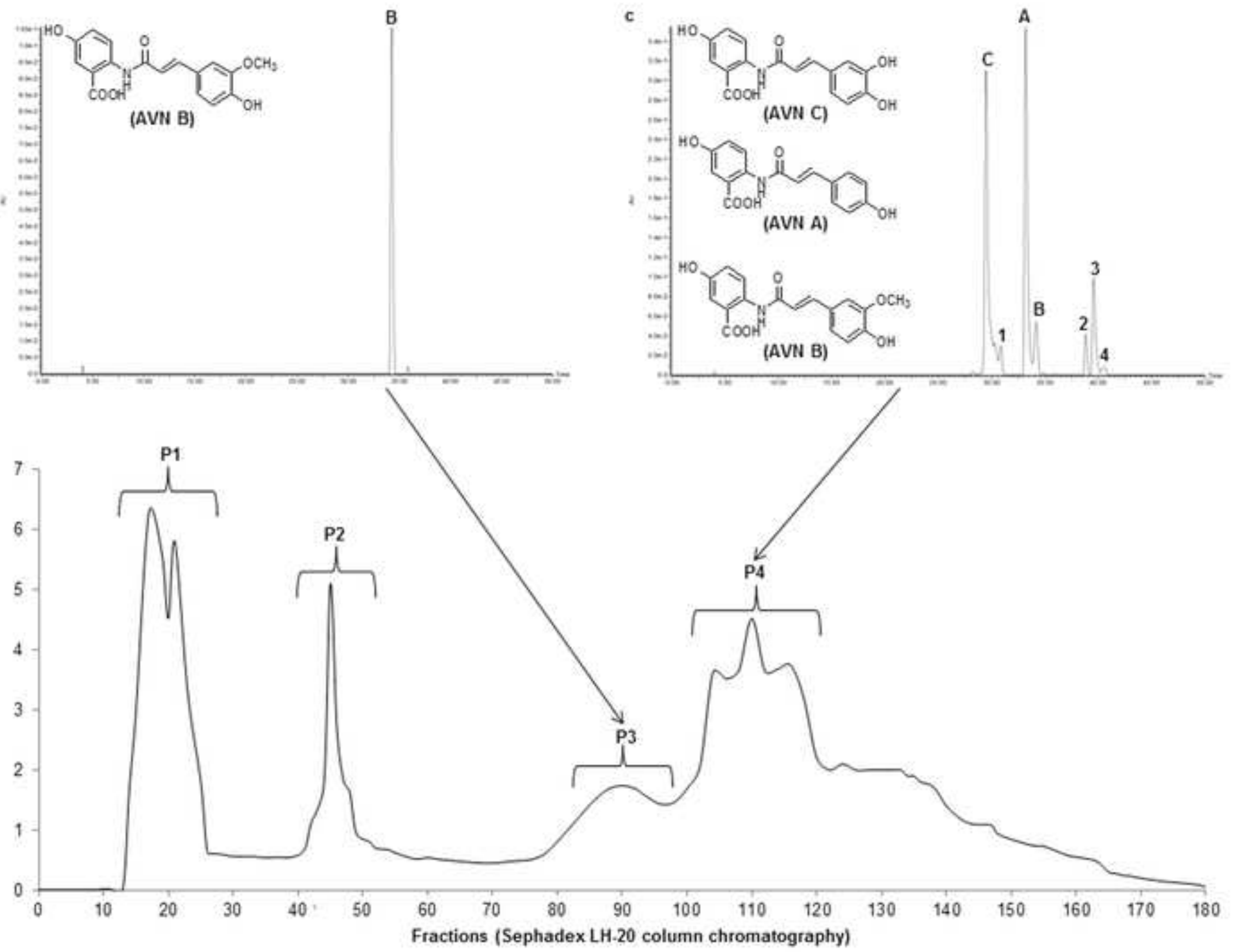




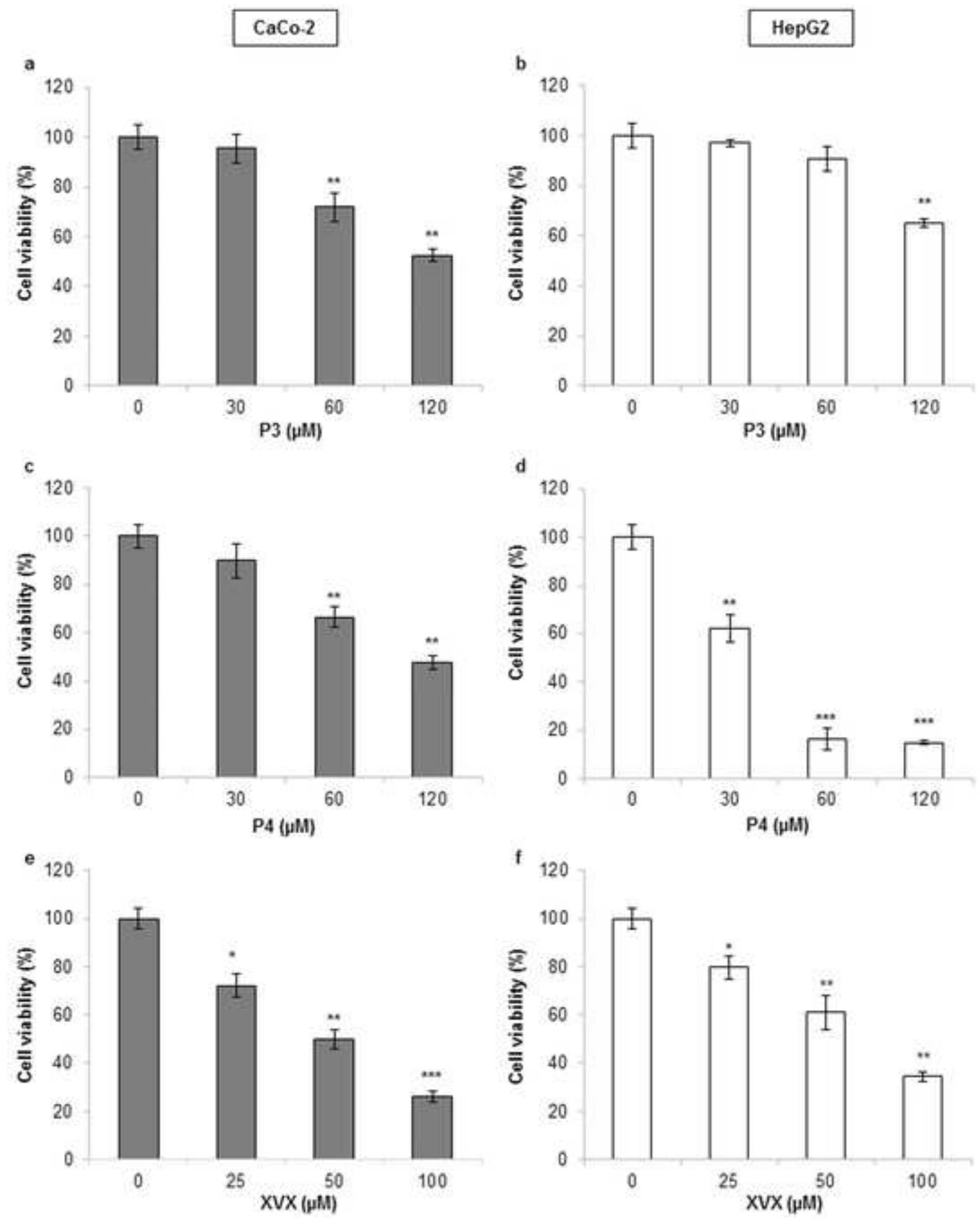




\section{$\mathrm{CaCO}-2$}

a

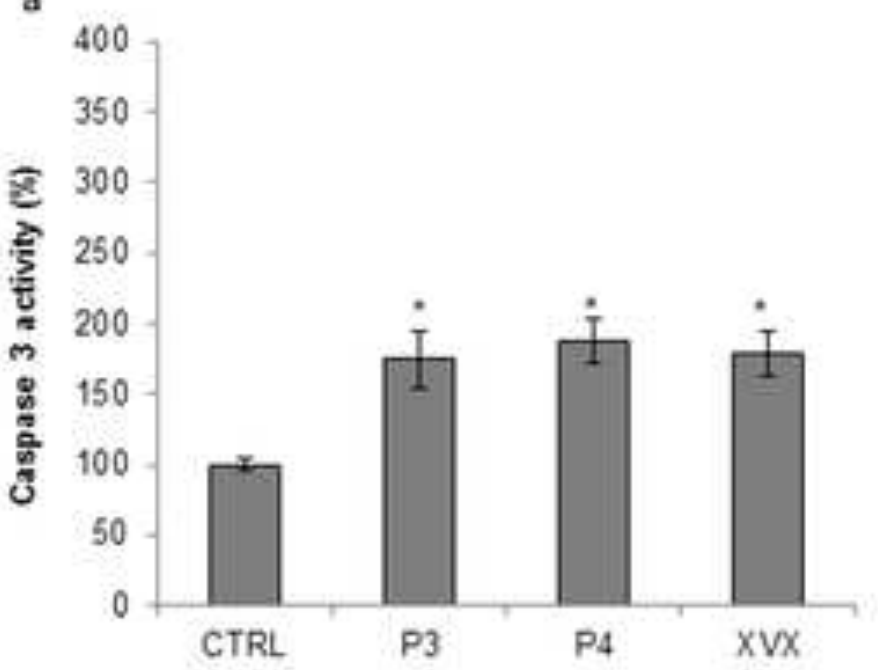

c
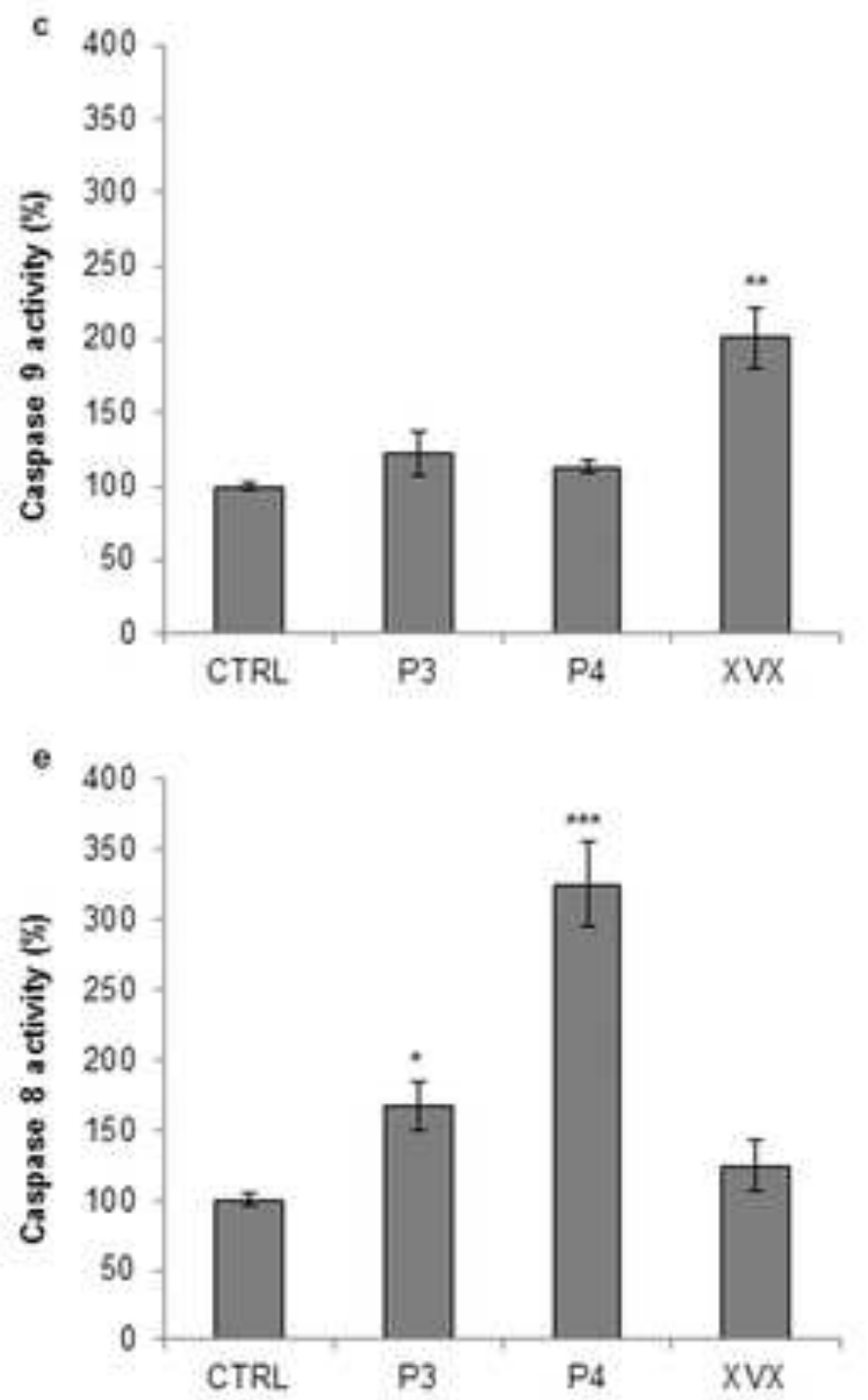

b
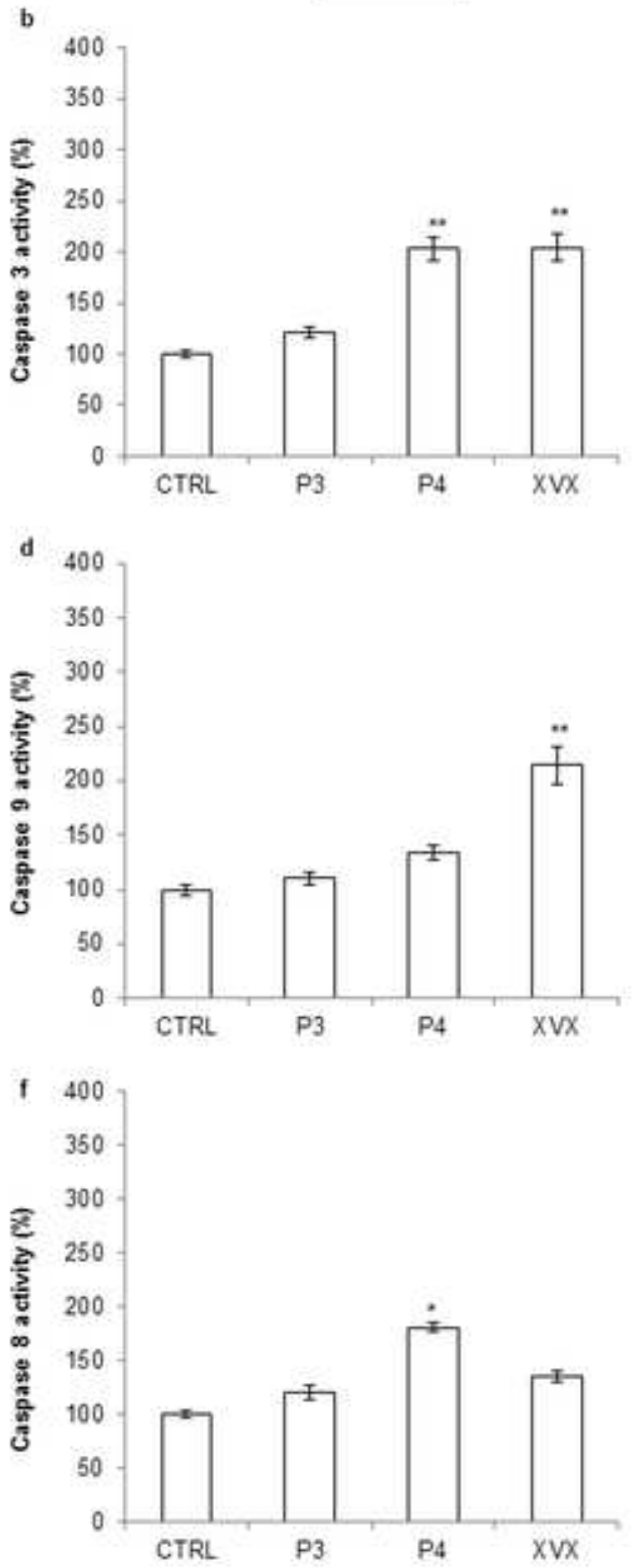


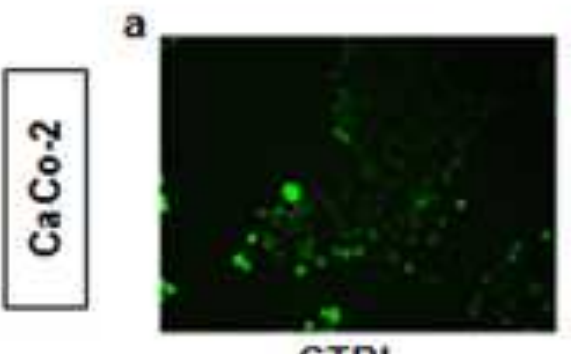

CTRL

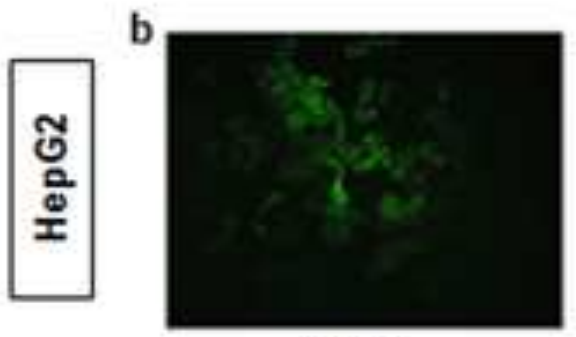

CTRL

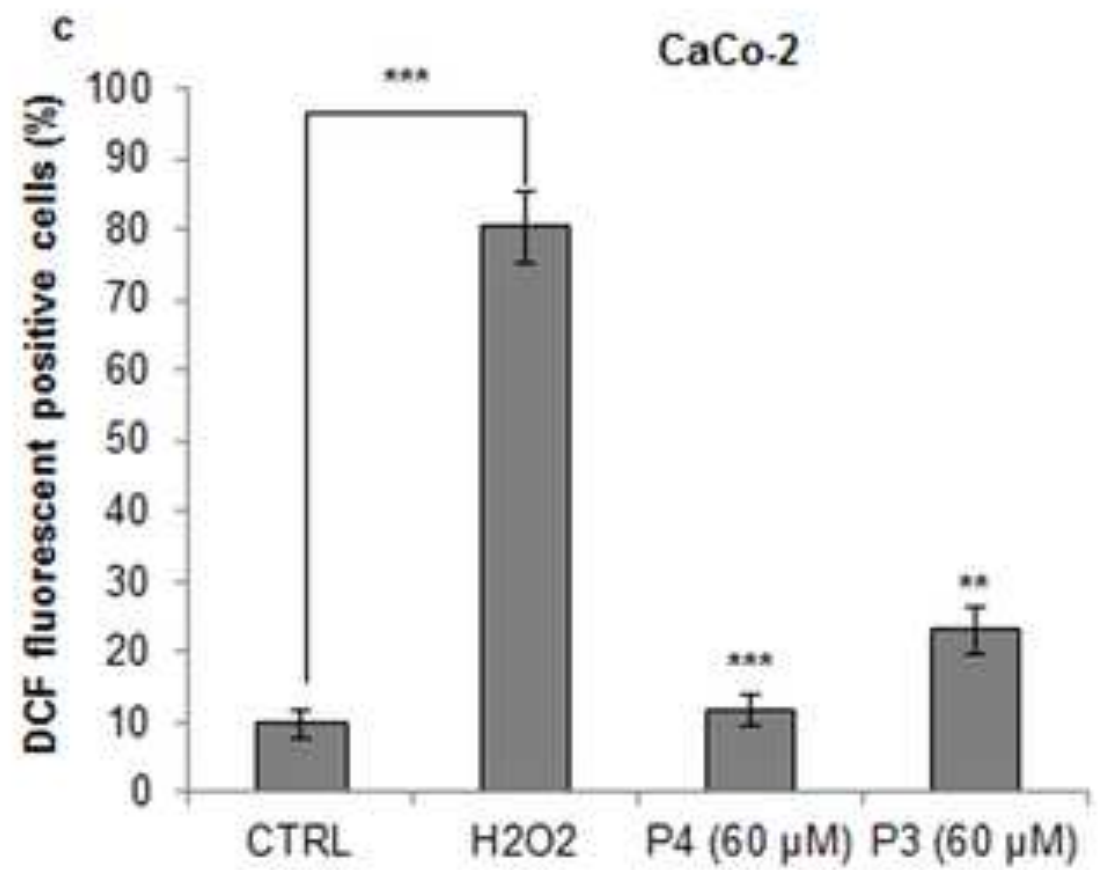

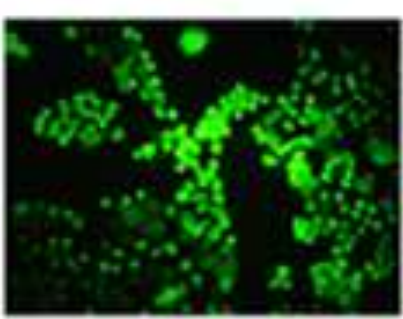

$\mathrm{H}_{2} \mathrm{O}_{2}$

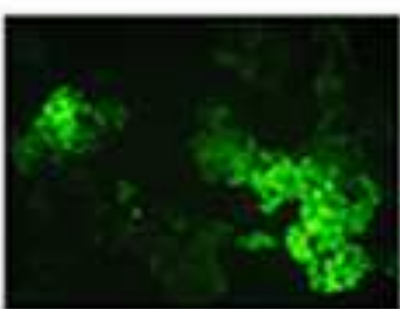

$\mathrm{H}_{2} \mathrm{O}_{2}$

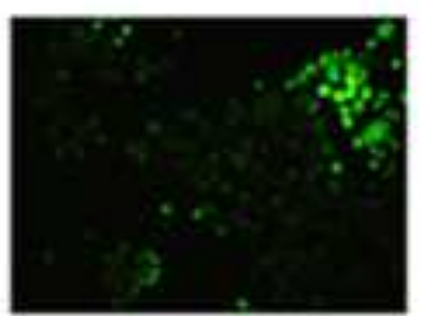

P4 (60 $\mu M)$

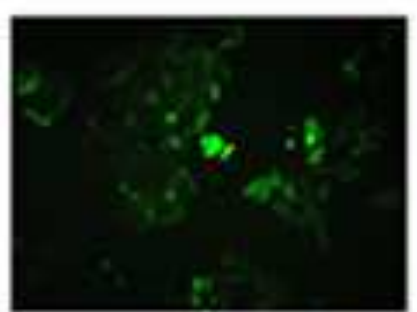

P4 (30 $\mu M)$

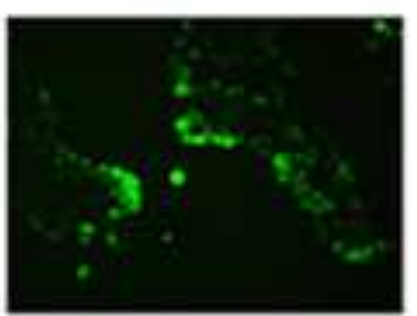

P3 (60 $\mu M)$

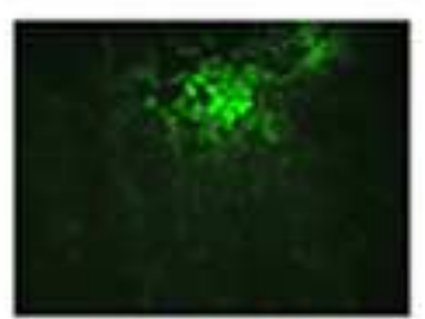

P3 $(120 \mu \mathrm{M})$

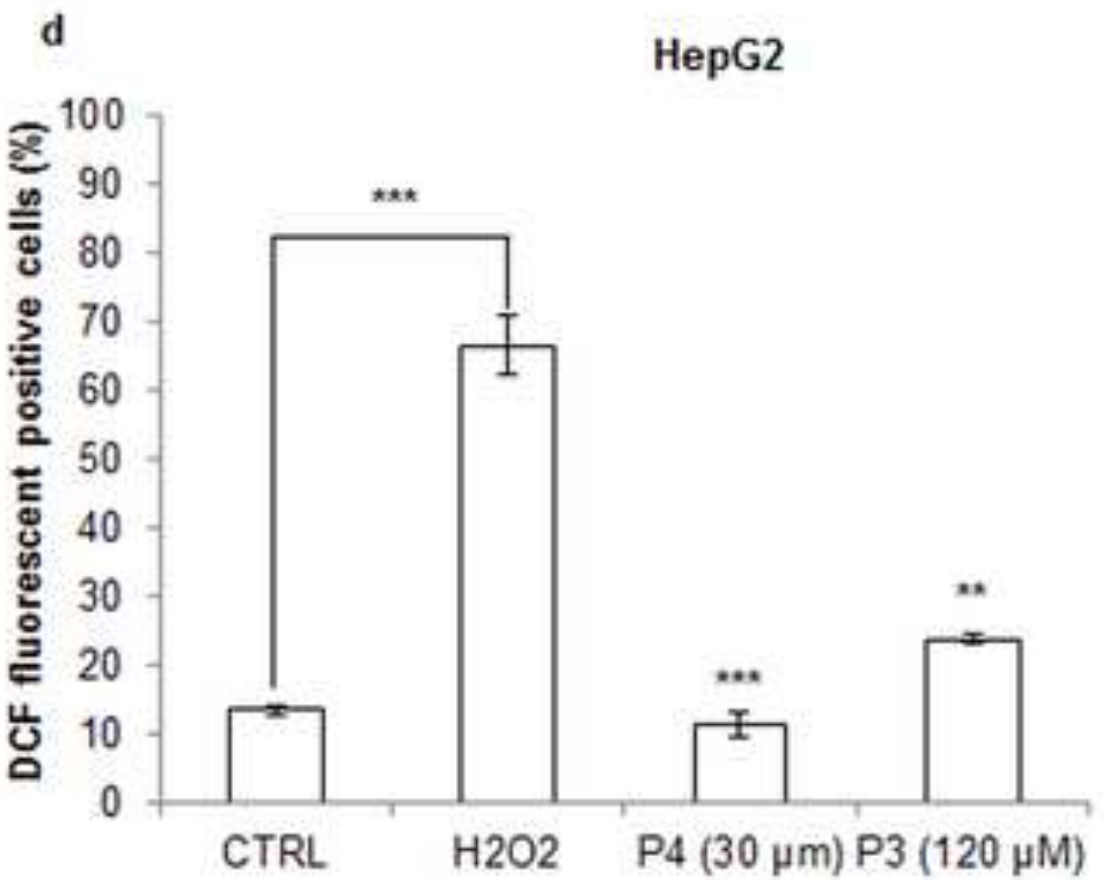



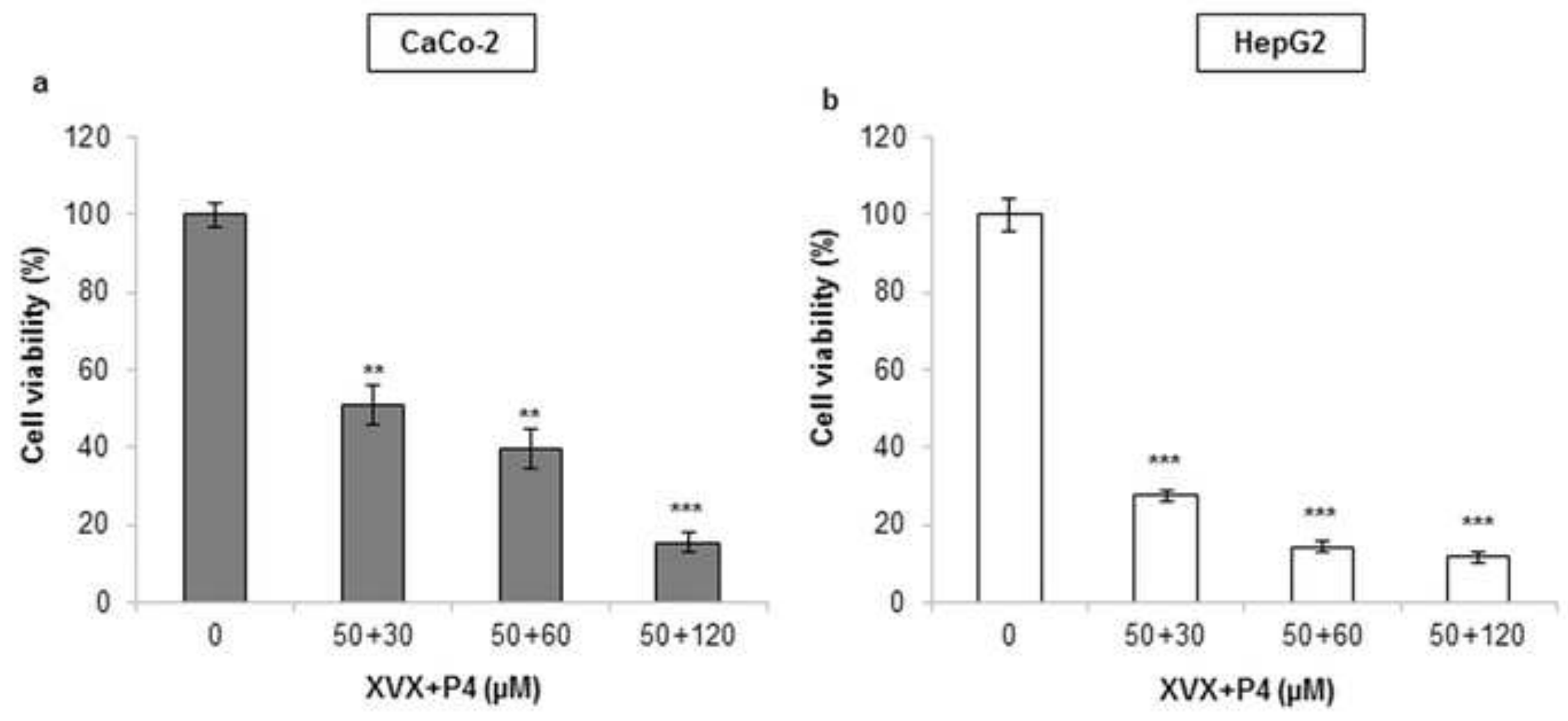


\section{CaCo-2}

a
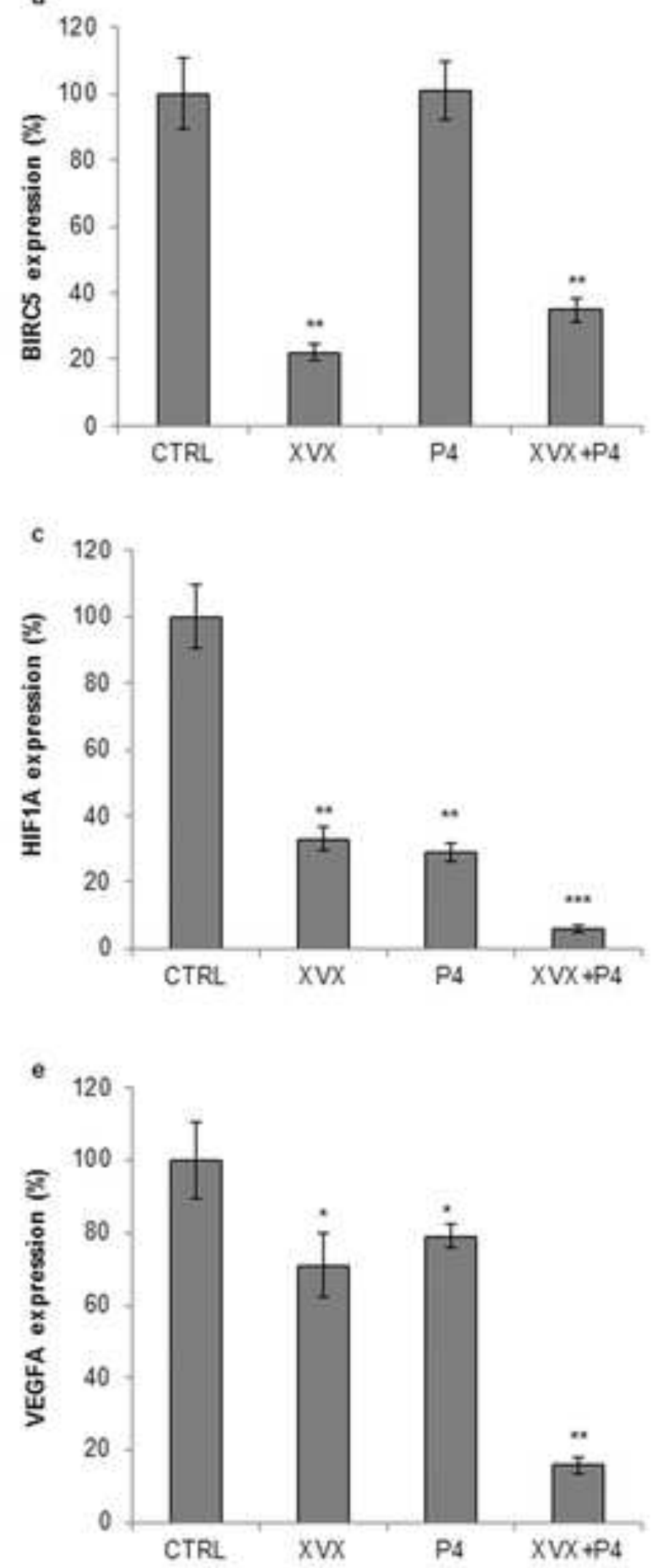

b
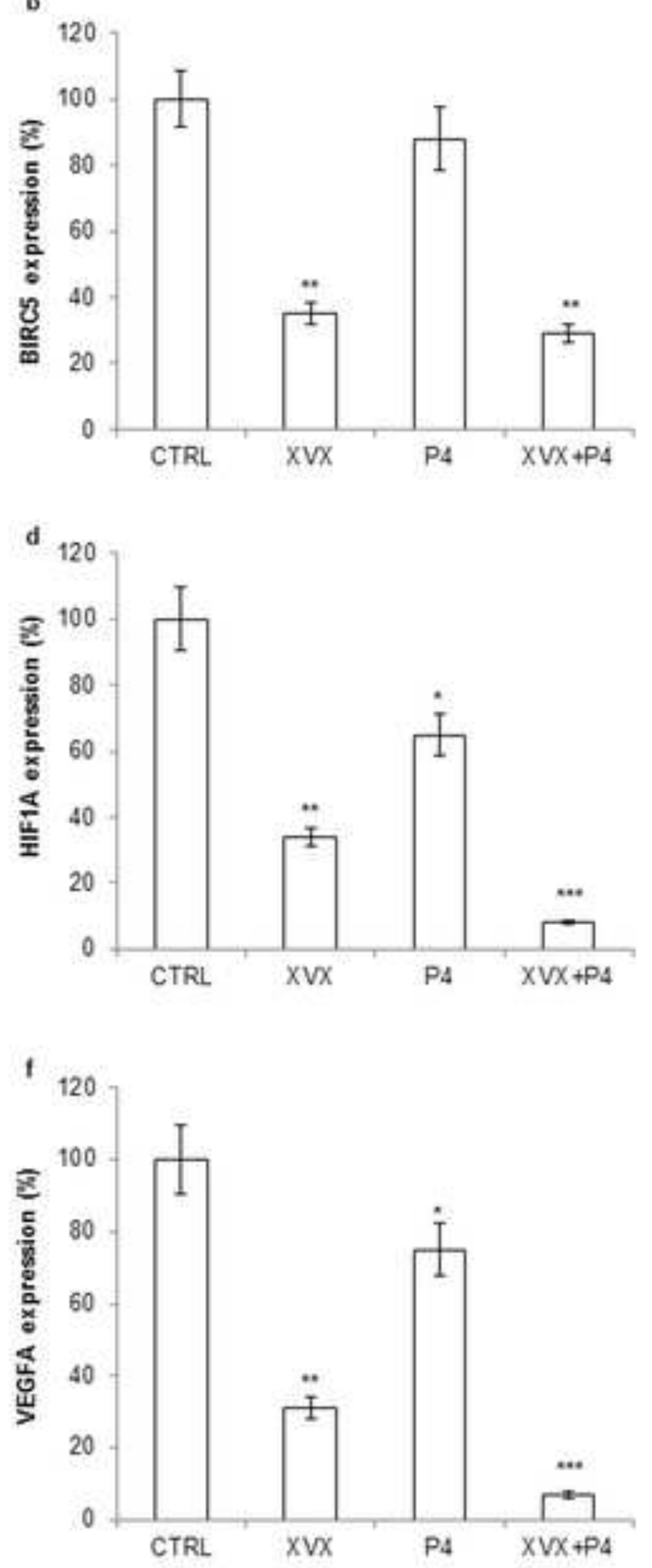
Table 1. HPLC-PDA-MS characterization of AVNs purified from $\mathrm{P} 3$ and $\mathrm{P} 4$ fractions and antioxidant capacity (ORAC) of the dried fractions.

\begin{tabular}{lcccccc}
\hline & $\begin{array}{c}\text { AVN } \\
\text { type }\end{array}$ & $\mathbf{t}^{\mathbf{a}}$ & $\boldsymbol{\%}^{\mathbf{b}}$ & $\mathbf{m}^{\mathbf{a}} \mathbf{z}^{\mathbf{a}}$ & $\mathbf{U V}^{\mathbf{a}}$ & $\begin{array}{c}\text { ORAC } \\
\left(\boldsymbol{\lambda}_{\max }\right)\end{array}$ \\
\hline P3 & B & 34.2 & $95 \pm 2$ & 329 & 342 & $6,547 \pm 290$ \\
& & & & & & \\
& C & 29.4 & $37 \pm 2$ & 315 & 343 & \\
P4 & A & 33.1 & $35 \pm 1$ & 299 & 319 & $19,079 \pm 474$ \\
& B & 34.2 & $8 \pm 1$ & 329 & 342 & \\
\hline
\end{tabular}

\footnotetext{
${ }^{\mathrm{a}} \mathrm{t}_{\mathrm{R}}, \mathrm{m} / \mathrm{z}, \mathrm{UV}$ spectra were compared with those of the external AVN A, B, $\mathrm{C}$ standards, and the peak areas were used for quantification.

${ }^{\mathrm{b}}$ AVN average percentages found in the P3 and P4 fractions, obtained from three different purification batches.
} 
Table 2. Caspases 3, 9 and 8 activity levels, after $48 \mathrm{~h}$ treatment with $\mathrm{XVX}+\mathrm{P} 4$ combination, on CaCo-2 and HepG2 cells.

\begin{tabular}{ccc|cc}
\hline & \multicolumn{2}{c|}{ CaCo-2 } & \multicolumn{2}{c}{ HepG2 } \\
& CTRL & XVX + P4 & CTRL & XVX+P4 \\
\hline Caspase 3 & $100 \pm 5$ & $229 \pm 17^{* *}$ & $100 \pm 4$ & $352 \pm 47^{* * *}$ \\
Caspase 9 & $100 \pm 3$ & $205 \pm 14^{* *}$ & $100 \pm 5$ & $229 \pm 26^{* *}$ \\
Caspase 8 & $100 \pm 4$ & $309 \pm 16^{* * *}$ & $100 \pm 3$ & $191 \pm 21^{*}$ \\
\hline
\end{tabular}

Three replicate experiments with two samples analyzed for each replicate $(n=6)$ were performed. ${ }^{*} \mathrm{p}<0.05,{ }^{* *} \mathrm{p}<0.01,{ }^{* * *} \mathrm{p}<0.001$. Cells were treated with $50 \mu \mathrm{M} \mathrm{XVX}+120 \mu \mathrm{M}$ P4. 


\section{Click here to access/download \\ Electronic Supplementary Material ESM_1.pdf}

